\title{
Sobrevivência e viabilidade de escleródios de Sclerotium rolfsii no solo
}

\author{
Leandro Luiz Marcuzzo ${ }^{1}$, Aline Schuller ${ }^{1,2}$
}

${ }^{1}$ Instituto Federal Catarinense - IFC/Campus Rio do Sul, CP 441, CEP 89.163-356, Rio do Sul, SC. ${ }^{2}$ Aluna do curso de Agronomia e Bolsista PET - Agroecologia IFC/Campus Rio do Sul.

Autor para correspondência: Leandro Luiz Marcuzzo (marcuzzo@ifc-riodosul.edu.br)

Data de chegada: 11/11/2013. Aceito para publicação em: 16/06/2014.

$10.1590 / 0100-5405 / 1951$

\section{RESUMO}

Marcuzzo, L.L.; Schuller, A. Sobrevivência e viabilidade de escleródios de Sclerotium rolfsii no solo. Summa Phytopathologica, v.40, n.3, p.281-283, 2014.

Em experimento de campo quantificou-se a sobrevivência e a viabilidade de escleródios de Sclerotium rolfsii no solo. Cinquenta e dois escleródios multiplicados em meio de cultura BDA foram colocados em saquinhos feito de tecido. Em armação de madeira contendo solo, colocaram-se 18 repetições respectivamente na superfície e enterrados a 10 centímetros. Mensalmente os saquinhos foram retirados de cada posição, lavados em água corrente e submetidos à compressão com dedo para constatar-se os mesmos mantinham-se intactos. Os escleródios intactos foram submetidos à assepsia com álcool $70 \%$ e hipoclorito de sódio $1 \%$ por um minuto e em seguida depositado em placas contendo meio BDA e acondicionado em câmara de crescimento a $25^{\circ} \mathrm{C}$ sem luz. Três dias após a incubação realizava-se a contagem dos escleródios germinados. Os escleródios coletados na superfície perderam sua viabilidade após oito meses e os enterrados permaneceram viáveis até o décimo quinto mês. Os escleródios de $S$. rolfsii na superfície tendem a perderem sua viabilidade num período de tempo menor que os enterrados.

Palavras-chave adicionais: Estrutura de repouso, longevidade, viabilidade.

\section{ABSTRACT}

Marcuzzo, L.L.; Schuller, A. Survival and viability of sclerotia from Sclerotium rolfsii on the soil. Summa Phytopathologica, v.40, n.3, p.281$283,2014$.

In a field experiment, the survival and the viability of Sclerotium rolfsii sclerotia on the soil were quantified. Fifty-two sclerotia multiplied on PDA culture medium were placed in fabric bags. In a wooden frame containing soil, 18 replicates were placed on the surface and buried at $10 \mathrm{~cm}$ depth, respectively. The bags were monthly removed from each position, washed under running water and compressed with the finger to verify whether they kept intact or not. Intact sclerotia underwent sterilization with $70 \%$ alcohol and $1 \%$ sodium hypochlorite for one minute; then, they were deposited on plates containing PDA culture medium and stored in a growth chamber at 25 ${ }^{\circ} \mathrm{C}$ in the absence of light. Three days after incubation, germinated sclerotia were counted. Sclerotia collected from the surface lost their viability after eight months, while buried ones kept viable until the fifteenth month. $S$. rolfsii sclerotia on the surface tend to lose their viability in a shorter period than buried ones.

Additional keywords: Resting structure, longevity, viability

Sclerotium rolfsii é um importante fitopatógeno habitante do solo, sendo responsável por causar sintomas de podridão de raízes, do colo, de bulbos e frutos, causando murcha, tombamento de plântulas e podridões. Apresenta extensa gama de hospedeiros, cerca de 200 espécies de plantas, pertencentes a quase 100 famílias botânicas, incluindo dicotiledôneas e monocotiledôneas, distribuindo-se em todas as regiões agrícolas do país com predominância nos estados de MG, PE, SP, DF, BA, SC, TO, ES, PB, RS $(1,2,8)$. Solos muito infestados por $S$. rolfsii podem ficar comprometidas para o cultivo de muitas espécies, entre elas alcachofra, alface, alho, cebola, batata, cajueiro, cenoura, ervilha, feijão, fumo, gergelim, girassol, mangueira, menta, plantas ornamentais, soja, solanáceas, sorgo e tomateiro (5).

As referências sobre a biologia de sobrevivência de escleródios de $S$. rolfsii citam que esses podem sobreviver no solo por no mínimo um ano (2), mas sem detalhes adicionais do comportamento ao logo do tempo e seu posicionamento no solo. Mediante a este aspecto, o objetivo desse trabalho foi avaliar a sobrevivência e viabilidade de sobrevivência de escleródios de $S$. rolfsii localizados na superfície e enterrados a $10 \mathrm{~cm}$ da superfície do solo em condição de pousio.

Os escleródios de $S$. rolfsii foram coletados de plantas de cebola e após a assepsia com álcool $70 \%$, hipoclorito de sódio $1 \%$ por 1 minuto foram multiplicados colocou-se um escleródio por placa de Petri contendo meio de cultura BDA comercial $\left(39\right.$ g. $\left.\mathrm{L}^{-1}\right)$ e incubados á $25^{\circ} \mathrm{C}$ em câmara de crescimento no escuro por trinta dias. Após a multiplicação, foi realizado o teste de avaliação de sobrevivência, onde 52 escleródios foram colocados dentro de saquinhos $(10 \times 5 \mathrm{~cm})$ confeccionados de tecido "voal" amarrados na extremidade com barbante. Os recipientes com os escleródios foram depositados a campo protegidos lateralmente em uma armação de madeira de 1 $\mathrm{m}^{2}$ com $0,2 \mathrm{~m}$ de profundidade contendo solo $(\mathrm{pH} \mathrm{6,5),} \mathrm{onde} 18$ recipientes foram depositados na superfície e 18 enterrados a 10 
Tabela 1. Número de escleródios intactos e viáveis e seu respectivo percentual de viabilidade de germinação ao longo de 18 meses localizados na superfície e enterrados a $10 \mathrm{~cm}$ no solo. IFC/Campus Rio do Sul, 2013

\begin{tabular}{|c|c|c|c|c|c|c|}
\hline \multirow{2}{*}{ Mês/ano } & \multicolumn{3}{|c|}{ Escleródios da superfície } & \multicolumn{3}{|c|}{ Escleródios enterrados } \\
\hline & Intactos $\left(n^{\circ}\right)$ & Viáveis $\left(\mathbf{n}^{0}\right)$ & Viabilidade (\%) & $\operatorname{Intactos}\left(n^{0}\right)$ & Viáveis $\left(n^{0}\right)$ & Viabilidade (\%) \\
\hline Jan/12 & 39 & 20 & 38 & 40 & 30 & 58 \\
\hline Fev/12 & 40 & 39 & 75 & 12 & 12 & 23 \\
\hline Mar/12 & 17 & 15 & 29 & 50 & 50 & 96 \\
\hline $\mathrm{Abr} / 12$ & 12 & 12 & 23 & 7 & 5 & 10 \\
\hline Mai/12 & 31 & 31 & 60 & 29 & 28 & 54 \\
\hline Jun/12 & 11 & 9 & 17 & 1 & 1 & 2 \\
\hline Jul/12 & 0 & 0 & 0 & 8 & 8 & 15 \\
\hline Ago/12 & 0 & 0 & 0 & 17 & 17 & 33 \\
\hline Set/12 & 1 & 1 & 2 & 3 & 3 & 6 \\
\hline Out/12 & 0 & 0 & 0 & 8 & 5 & 10 \\
\hline Nov/12 & 0 & 0 & 0 & 0 & 0 & 0 \\
\hline Dez/12 & 0 & 0 & 0 & 0 & 0 & 0 \\
\hline Jan/13 & 0 & 0 & 0 & 2 & 2 & 4 \\
\hline $\mathrm{Fev} / 13$ & 0 & 0 & 0 & 0 & 0 & 0 \\
\hline Mar/13 & 0 & 0 & 0 & 1 & 1 & 2 \\
\hline $\mathrm{Abr} / 13$ & 0 & 0 & 0 & 0 & 0 & 0 \\
\hline Mai/13 & 0 & 0 & 0 & 0 & 0 & 0 \\
\hline Jun/13 & 0 & 0 & 0 & 0 & 0 & 0 \\
\hline
\end{tabular}

centímetros de profundidade no solo. Mensalmente, de janeiro de 2012 a junho de 2013, foi realizado o teste de sobrevivência dos escleródios, onde foi coletado um saquinho em cada posição. Os saquinhos foram lavados em água de torneira para remoção do solo aderido. Em seguida foi avaliada a rigidez do escleródio através de pressão manual do dedo indicador na superfície de uma mesa, caso não se desintegrasse era considerado intacto. Os escleródios intactos foram levados para câmara de fluxo laminar e submetidos à assepsia e foram depositados em placas de Petri contendo BDA. Após as placas foram colocadas em câmara de crescimento a 25 ${ }^{\circ} \mathrm{C}$. A viabilidade foi avaliada pela contagem da germinação de escleródios após três dias de incubação.

Os escleródios da superfície tiveram um comportamento variado e o decréscimo do número de escleródios viáveis não foi constante, permanecendo assim até junho de 2012. Observou-se que no mês de maio os escleródios viáveis foram mais que o dobro do mês de abril (Tabela 1). Em Janeiro ocorreu a maior diferença entre escleródios intactos e viáveis, tendo uma redução significativa de quase $50 \%$. Nos meses de julho e agosto de 2012, nenhum escleródio foi coletado e em setembro apenas um escleródio permaneceu intacto, representando $2 \%$ de viabilidade da população. A partir de setembro de 2012 nenhum escleródio intacto foi coletado, totalizando uma sequência de nove meses sem coleta de escleródios (Tabela 1).

A sobrevivência dos escleródios enterrados a $10 \mathrm{~cm}$ de profundidade se estendeu até março de 2013, totalizando 15 meses (Tabela 1). Nos meses de janeiro e outubro de 2012 foram registrados os menores valores de escleródios viáveis em relação aos intactos com $75 \%$ e $62,5 \%$ respectivamente. A partir de outubro de 2012 até fevereiro de 2013 apenas $4 \%$ da população se manteve viável e em março de 2013 a população viável foi de $2 \%$ (Tabela 1 ).

S. rolfsii é um patógeno facultativo capaz de se desenvolver nas camadas superficiais do solo e que sobrevive melhor na superfície do solo do que enterrado (1). Porém, o oposto ocorreu neste trabalho, em que os enterrados apresentaram maior sobrevivência (Tabela 1), possivelmente devido à estabilidade das condições ambientais, já que na superfície do solo estão sujeitos a ciclos de secagem e molhamento e são afetados pela degradação da radiação solar, temperatura e/ou falta de umidade, desta forma germinaram antes do que os enterrados (6). No entanto, Bueno et al. (3) não constataram alteração na sobrevivência dos escleródios $S$. rolfsii na superfície e enterrados a $10 \mathrm{~cm}$ nas condições de Botucatu, SP, durante os primeiros 6 meses. Isso possivelmente reflete que a sobrevivência do patógeno esteja relacionada às condições climáticas do local.

Reis \& Tomazini (7) avaliando a sobrevivência de escleródios de Sclerotinia sclerotiorum verificaram que os escleródios enterrados tiveram 36 meses de viabilidade enquanto que os localizados na superfície do solo apenas 14 meses. Isso ocorreu também nesse trabalho, porque os escleródios enterrados permanecem úmidos, fazendo que tenham uma dormência maior e menor germinação, enquanto que os da superfície estão sujeitos a ciclos de secagem e molhamento e desta forma germinam antes dos enterrados (4).

Mediante aos resultados constatou-se um decréscimo da sobrevivência e viabilidade dos escleródios de $S$. rolfsii, onde os enterrados a $10 \mathrm{~cm}$ permaneceram viáveis por quinze meses enquanto que os da superfície não passaram de nove meses.

\section{REFERÊNCIAS BIBLIOGRÁFICAS}

1. Barreto, M. Doenças do amendoim. In: Kimati, H.; Amorim, L.; Bergamin Filho, A.; Camargo, L.E.A. Manual de fitopatologia. doenças de plantas cultivadas. 4. ed. São Paulo: Ceres, 1997. v.2, Cap. 10, p.65-72.

2. Bianchini, A.; Maringoni, A.C.; Carneiro, S.M.T.P.G. Doenças do feijoeiro. In: Kimati, H.; Amorim, L.; Bergamin Filho, A.; Camargo, L.E.A. Manual de fitopatologia. doenças de plantas cultivadas. 4. ed. São Paulo: Ceres, 1997. v.2, Cap.37, p.333-349.

3. Bueno, C. J.; Ambrósio, M. M. Q.; Souza, N. L. Produção e avaliação da sobrevivência de estruturas de resistência de fungos fitopatogênicos habitantes do solo. Summa Phytopathologica, Botucatu, v.33, n.1, p.47-55, 2007.

4. Ferraz, L. C. L.; Café Filho, A. C.; Nasser, L. C. B.; Azevedo, J. Effects of soil moisture, organic matter and grass mulching on the carpogenic germination of sclerotinia and infection of bean by Sclerotinia sclerotiorum. Plant Pathology, Edinburgh, v.48, n.7, p.77-82, 1999.

5. Kimati, H.; Amorim, L.; Rezende, J. A. M.; Bergamim Filho, A.; Camargo, L.E.A. Manual de fitopatologia: doenças das plantas cultivadas. 3 ed. São 
Paulo: CERES, 1997. v.2, 706p.

6. Martins, M. V. V.; Silveira, S. F.; Mussi-Dias, V.; Vieira, H. D. Efeito da temperatura e umidade do substrato na viabilidade de Sclerotium rolfsii. Acta Scientiarum Agronomy, Maringá, v.32, n.2, p.217-222, 2010.

7. Reis, E. M.; Tomazini, S. L. Viabilidade de escleródios de Sclerotinia sclerotiorum em duas profundidades de solo. Summa Phytopathologica, Botucatu, v.31, n.3, p.97-99, 2005.

8. Schurt, D.A Potencial do isotilcianato e alilo no controle de Sclerotium rolfsii e Sclerotinia sclerotiorum. 2006. 57 f. Dissertação (Mestrado em Fitopatologia) Universidade Federal de Viçosa, Viçosa, 2006. 